José Haba-Rubio

Georges Darbellay

François R. Herrmann

Jean G. Frey

Alda Fernandes

Jean M. Vesin

Jean P. Thiran

Jean M. Tschopp

\section{Obstructive sleep apnea syndrome: effect of respiratory events and arousal on pulse wave amplitude measured by photoplethysmography in NREM sleep}

Published online: 4 May 2005

(C) Springer-Verlag 2005

J. Haba-Rubio · J. G. Frey · A. Fernandes ·

J. M. Tschopp ( $\square)$

Sleep Laboratory,

Centre Valaisan de Pneumologie,

3963 Crans-Montana, Switzerland

e-mail: jean-marie.tschopp@admin.vs.ch

Fax: +41-27-6038181

G. Darbellay · J. M. Vesin · J. P. Thiran Institute for Signal Processing Laboratory, Swiss Federal Institute of Technology, Lausanne, Switzerland

F. R. Herrmann

Departments of Rehabilitation and

Geriatrics, University Hospitals,

Geneva, Switzerland

\begin{abstract}
The objective of the study is to evaluate changes in finger pulse wave amplitude (PWA), as measured by photoplethysmography, and heart rate (HR), related to obstructive respiratory events and associated arousals during sleep. We analyzed 1,431 respiratory events in NREM sleep from 12 patients according to (1) the type of event (apnea, hypopnea, upper airway resistance episode) and (2) the duration of the associated EEG arousal $(>10,3-10,<3 \mathrm{~s})$. Obstructive respiratory events provoked a relative bradycardia and vasodilation followed by HR increase and vasoconstriction. Relative PWA changes were significantly greater than HR changes. These responses differed significantly
\end{abstract}

according to EEG-arousal grades (time $\times$ arousal interaction, $p<0.0001$ ), with longer arousals producing greater responses, but not to the type of respiratory event (time $\times$ event interaction, $p=\mathrm{ns}$ ). Obstructive respiratory events provoke HR and PWA changes, the magnitude seemingly related to the intensity of central nervous activation, with PWA changes greater than HR. PWA obtained from a simple pulse oxymeter might be a valuable method to evaluate sleep fragmentation in sleep breathing disorders.

Keywords Obstructive sleep apnea · Arousal $\cdot$ Autonomic markers $\cdot \mathrm{O}_{2}$ pulse wave amplitude

\section{Introduction}

Sleep-disordered breathing (SDB) covers a spectrum from complete upper airway obstruction [obstructive sleep apnea (OA) [ [1] to more subtle breathing abnormalities [obstructive hypopnea $(\mathrm{OH})$, upper airway resistance episodes (UARE)] [2]. The termination of sleep respiratory events is thought to depend on arousal from sleep, which restores upper airway patency [3-5]. The arousal response is important for survival of the affected patient; however, the sleep fragmentation induced by repetitive arousals and the physiological events that surround the arousal response also have adverse consequences which contribute to the pathophysiology and clinical manifestations of SDB [5]. Arousals are characterized by abrupt changes in central nervous system activity that produce electroencephalogram (EEG) activation and marked changes in a wide range of autonomic nervous system parameters such as heart rate
(HR), blood pressure (BP), ventilation and peripheral vascular resistance [6-10]. Arousals are typically evident and conventionally detected as changes in cortical EEG activity, a labor-intensive approach associated with high interscorer variability [11]. In addition, according to the American Sleep Disorders Association (ASDA) definition [12], only about $75 \%$ of respiratory events are terminated by an EEG arousal [13], but it has been shown that stimuli that produce measurable cardiovascular disturbances without arousal appear sufficient to produce daytime sleepiness [14]. The term "autonomic arousal" is used to denote transient changes during sleep in autonomic parameters which are not necessarily associated with EEG arousals, and there is, consequently, considerable interest in using convenient, non-invasive autonomic markers of sleep fragmentation, particularly in SDB [15].

Parameters derived from peripheral vasoconstrictor responses appear to show dramatic changes following arousal 
$[6,10]$. Pulse wave amplitude (PWA) measured by photoplethysmography may have several advantages over other cardiovascular markers of arousal; thus, it can easily be recorded using most conventional pulse oxymeters already in sleep-laboratory use or in ambulatory screening devices. In previous studies, changes in PWA were measured by photoplethysmography in relation to arousals induced by acoustical stimulus in healthy subjects $[6,10]$. In sleeprelated breathing disorders, blood gas disturbances and other factors potentially further modulate activation-related autonomic activity $[16,17]$ and could modify this cardiovascular response. If reliable changes in PWA could be detected in relation to obstructive sleep respiratory events, the photoplethysmography could become an interesting screening method for detecting respiratory events and for assessing sleep fragmentation in obstructive sleep apnea patients.

The first aim of this preliminary study was, then, to determine if changes in PWA related to sleep respiratory events could be detected by photoplethysmography and to compare the relative PWA magnitude changes with changes in HR. The second aim was to determine if these changes were related to the nature of the stimuli (i.e., type of respiratory event) or if they were proportional to the intensity of the associated arousal.

\section{Materials and methods}

Patients

We analyzed data from 12 patients referred to our laboratory for evaluation because of presumed SDB. To qualify for the study, the patients had to fulfill the following criteria:

(1) Nocturnal polysomnography performed using esophageal pressure recording without technical problems during the monitoring and without artifacts on EEG tracings

(2) A confirmed diagnosis of SDB with a respiratory disturbance index $>30$ respiratory events per hour of sleep, at the end of the diagnostic procedure. We deliberately chose six patients who essentially presented OA and $\mathrm{OH}$ and six patients presenting a combination of $\mathrm{OH}$ and UARE

(3) Absence of unstable medical condition.

Patients were not considered for the study if they were taking psychoactive, cardiac, antihypertensive or drugs interfering with the autonomic system. They were informed that some of the collected data would be used for research purposes, and they gave written informed consent.
Measurements

Overnight polysomnography was performed according to standard laboratory protocol, with MAP polysomnography system (Monet 27 channels, MAP, Germany), between 2230 and $0600 \mathrm{~h}$ the following day. Signals recorded were as follows: EEG (C3-A2, O1-A2, C4-A1, O2-A1, sampling rate $125 \mathrm{~Hz}$ ), left and right electro-oculogram (EOG, sampling rate $100 \mathrm{~Hz}$ ), submental electromyogram (EMG, sampling rate $100 \mathrm{~Hz}$ ), arterial blood oxygen saturation $\left(\mathrm{SaO}_{2}\right)$ and finger photoplethysmogram (using Nonin XPOD3012 oxymeter, Nonin Medical Inc., Plymouth, MN, USA, sampling rates 20 and $80 \mathrm{~Hz}$, respectively), electrocardiogram (ECG, sampling rate $800 \mathrm{~Hz}$ ), chest and abdominal movements (sampling rate $20 \mathrm{~Hz}$ ), esophageal pressure (using a Jaeger esophagus catheter connected to a pressure transducer, sampling rate $50 \mathrm{~Hz}$ ) and surface EMG of the anterior tibialis muscles (sampling rate $100 \mathrm{~Hz}$ ). Respiratory airflow was monitored with a nasal cannula connected to a pressure transducer (Protech2, Minneapolis, MN, USA, sampling rate $20 \mathrm{~Hz}$ ). Snoring was measured by a microphone placed at the suprasternal notch. A body position sensor attached to a thoracic belt was used to monitor body position. Data were digitized, amplified and evaluated using sleep-stage software (Analysis Manager 7.18, MAP).

\section{Data analysis}

Sleep staging, arousal and respiratory events scoring Sleep staging was performed using the criteria of Rechtschaffen and Kales [18] for epochs of $20 \mathrm{~s}$.

In a first phase, respiratory events were scored by a single trained observer (J.H.) blinded to the cardiovascular channels and using standard criteria [1], irrespective of the presence or absence of EEG arousal. An OA was defined as a complete cessation of airflow for more than $10 \mathrm{~s}$. An $\mathrm{OH}$ was defined as a $50 \%$ or greater reduction in airflow from the baseline value lasting at least $10 \mathrm{~s}$ or a clear amplitude airflow reduction lasting $>10 \mathrm{~s}$ and associated with either an oxygen desaturation of $>3 \%$ or an arousal. An UARE was defined as a progressive change in the shape of the inspiratory flow contour (characterized by increasing limitation) and of an increase in respiratory effort (in a crescendo pattern), in the absence of decrease in airflow, with termination of the event as abrupt normalization of both inspiratory flow contour and the esophageal pressure swing. All obstructive respiratory events detected from stage 2 NREM sleep were included for cardiovascular analysis.

In a second phase, EEG changes related to the respiratory events were scored by the same investigator. Again, EEG changes related to all respiratory events from stage 2 
Table 1 Clinical, anthropometric and polysomnographic data for 12 patients

\begin{tabular}{lcccccccccccccc}
\hline & 1 & 2 & 3 & 4 & 5 & 6 & 7 & 8 & 9 & 10 & 11 & 12 & Mean & SEM \\
\hline Age (year) & 59 & 53 & 49 & 35 & 47 & 44 & 32 & 54 & 57 & 47 & 31 & 42 & 45.8 & 2.8 \\
Gender & $\mathrm{M}$ & $\mathrm{M}$ & $\mathrm{M}$ & $\mathrm{M}$ & $\mathrm{M}$ & $\mathrm{M}$ & $\mathrm{F}$ & $\mathrm{M}$ & $\mathrm{M}$ & $\mathrm{M}$ & $\mathrm{M}$ & $\mathrm{M}$ & \\
BMI (kg/m ${ }^{2}$ ) & 30.1 & 26.3 & 29.4 & 32.3 & 26.4 & 30.5 & 42.3 & 32.4 & 28.7 & 30 & 34 & 27.2 & 30.8 & 1.3 \\
ESS & 10 & 9 & 5 & 5 & 6 & 9 & 9 & 8 & 7 & 9 & 8 & 16 & 8.4 & 0.9 \\
RDI (no./h) & 64.4 & 31.9 & 58.8 & 73.2 & 30.9 & 37.6 & 54.4 & 77.6 & 34.7 & 65.6 & 30.2 & 37.6 & 49.7 & 5.2 \\
TST (min) & 325 & 289 & 339 & 414 & 236 & 343 & 354 & 348 & 372 & 299 & 331 & 325 & 331.3 & 13 \\
SE (\%TST) & 67 & 67 & 72 & 96 & 54 & 86 & 85 & 79 & 81 & 63 & 74 & 64 & 74 & 3.5 \\
Stage 1 (\% TST) & 20.7 & 10.8 & 11.2 & 11.4 & 10.2 & 17.3 & 4.2 & 12.8 & 22.1 & 9.5 & 13.2 & 15.3 & 13.2 & 1.5 \\
Stage 2 (\% TST) & 28.1 & 34.8 & 38.3 & 56.0 & 19.7 & 54.0 & 53.7 & 47.9 & 30.2 & 33.1 & 38.3 & 25.8 & 38.3 & 3.5 \\
Stage 3-4 (\% TST) & 7.2 & 26.8 & 16.9 & 17.9 & 24.2 & 15.4 & 6.4 & 1.5 & 15.9 & 14.2 & 14.9 & 17.1 & 14.9 & 2.1 \\
REM (\% TST) & 10.7 & 4.9 & 15.9 & 11.7 & 4.5 & 5.4 & 26.2 & 17.8 & 16.1 & 10.9 & 12.4 & 11.9 & 12.4 & 1.8 \\
AI (no./h) & 54.6 & 41.3 & 43.4 & 64.9 & 34.9 & 52.8 & 34.4 & 61.0 & 52.6 & 58.6 & 46.6 & 30.6 & 48 & 3.3 \\
\hline
\end{tabular}

$B M I$ Body mass index, ESS Epworth Sleepiness Scale score, RDI respiratory disturbance index, $T S T$ total sleep time, $S E$ sleep efficiency, $A I$ arousal index

NREM were considered for cardiovascular analysis. EEG changes were assessed on the central EEG leads (C3-A2, $\mathrm{C} 4-\mathrm{A} 1)$ and subdivided into three categories based on the duration of changes in EEG frequency: grade 2, shift in EEG frequency lasting $>10 \mathrm{~s}$ and including alpha activity and/or frequencies $>16 \mathrm{~Hz}$, according to the standard criteria of awakening [18]; grade 1, shift in EEG frequency lasting from 3 to $10 \mathrm{~s}$ and including alpha activity and/or frequencies $>16 \mathrm{~Hz}$, except spindles, according to standard criteria of microarousal [12]; grade 0, no EEG changes or minor EEG changes, usually not classified as arousals in the ASDA criteria (i.e., shifts in EEG frequency lasting $<3 \mathrm{~s}$, $\mathrm{K}$ complexes or delta wave bursts). Similar arousal categories have been used previously for the assessment of cardiovascular responses to arousal [10, 19-21]. Concordance in arousal classification between the scorer and an experienced sleep technician who scored a randomly chosen subsample of 400 events was $86 \%$. The intraobserver repeatability was $92 \%$.
A

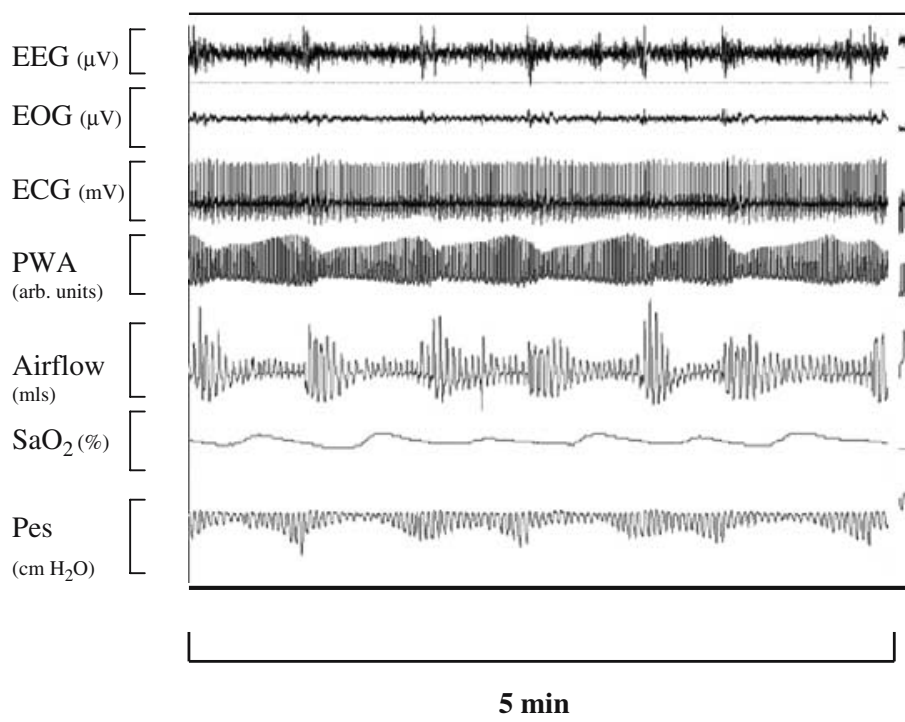

B

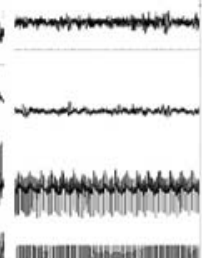

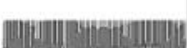

monoworownor
C

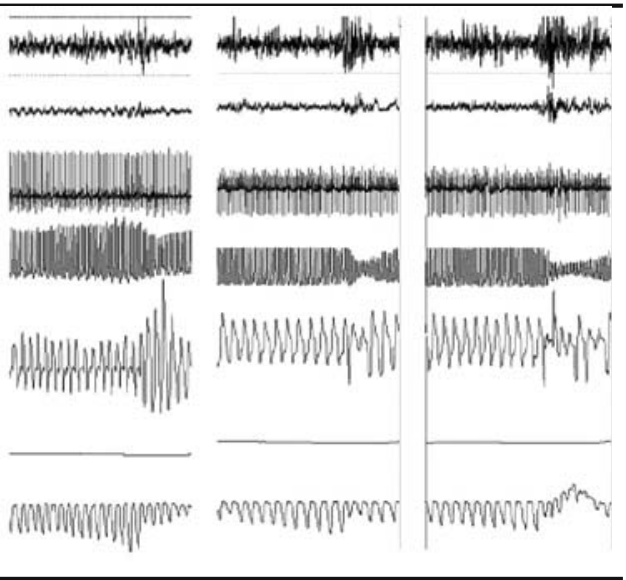

Fig. $1 A$ Five minutes polysomnographic recording during stage 2 NREM sleep with electroencephalogram $(E E G)$, electro-oculogram $(E O G)$, electrocardiogram $(E C G)$, finger pulse wave amplitude $(P W A)$, airflow, pulse oxymetry $\left(\mathrm{SaO}_{2}\right)$ and esophageal pressure $(P e s)$. The PWA obtained by PWA varied during obstructive hypopneas $(\mathrm{OH})$ and was prominently reduced during arousal and hyper- ventilation. $B-E$ Representative tracings, respectively, during a "nonevent" period (regular and stable breathing pattern without arousal), an upper airway resistance episode (UARE) with a grade 0 arousal (no changes or minor EEG changes $<3 \mathrm{~s}$ ), UARE accompanied by a grade 1 arousal (3- to 10 -s EEG arousal) and UARE that elicited a grade 2 arousal ( $>10-\mathrm{s}$ EEG arousal) 
Cardiovascular responses The end of the respiratory event was determined at the beginning of the inspiration of the first unobstructed breath, based on normalization of the esophageal pressure swing. The last 12 cardiac cycles during the respiratory event and the first 18 cycles immediately following its end were considered for analysis. In addition, we similarly analyzed at least 20 "non-events" per patient (ten at the beginning and ten at the end of the night) during periods of regular and stable breathing pattern without arousal in stage 2 NREM sleep.

Twelve cardiac cycles correspond, approximately (for a heart rate of $70 \mathrm{bpm}$ ) to $10 \mathrm{~s}$, and 18 cardiac cycles correspond approximately to $15 \mathrm{~s}$. Similar periods on average have previously been used for analyzing cardiovascular changes related to obstructive sleep apneas [22], allowing us to avoid cardiovascular interference from a previous respiratory event. The analysis of the 18 cardiac cycles following the end of the respiratory event may allow to detect the maximal related changes [23]. A much longer period analysis could be influenced by the occurrence of the next respiratory event, when one event is closely followed by another one.

The HR was determined from the R-R interval. Finger PWA was determined as the difference between the peak and the nadir values of the corresponding photoplethysmogram pulse waveform for each cardiac cycle.

To characterize the pattern of cardiovascular changes that occurred in relation to each respiratory event, for each cardiovascular marker (HR, PWA), we calculated the mean of all 30 values ( 12 before and 18 after the end of the event) and expressed each value as a percentage of this average. We looked at the maximal cardiovascular response to each respiratory event, i.e., the highest (for HR) or lowest (for PWA) value of each parameter recorded after the end of the respiratory event. We also calculated the difference between the lowest value at the end of the respiratory event and the highest value after its end for HR $(\Delta \mathrm{HR})$, and the difference between the highest value at the end of the respiratory event and the lowest value after its end for PWA ( $\triangle \mathrm{PWA})$. The greatest change after the respiratory event and the $\Delta$ values were also expressed as a percentage of the mean of all 30 values calculated for each event.

In this way, relative magnitude changes of cardiovascular response associated with different types of sleeprelated respiratory event (OA, OH and UARE) and with different levels of arousal following these events (grades 0 , 1 and 2) could be compared within and between subjects. Replicate responses for each patient were subsequently averaged and used to calculate group mean responses.

\section{Statistical analysis}

Differences in cardiovascular responses (HR, PWA) were assessed using analysis of variance (ANOVA) with a re-

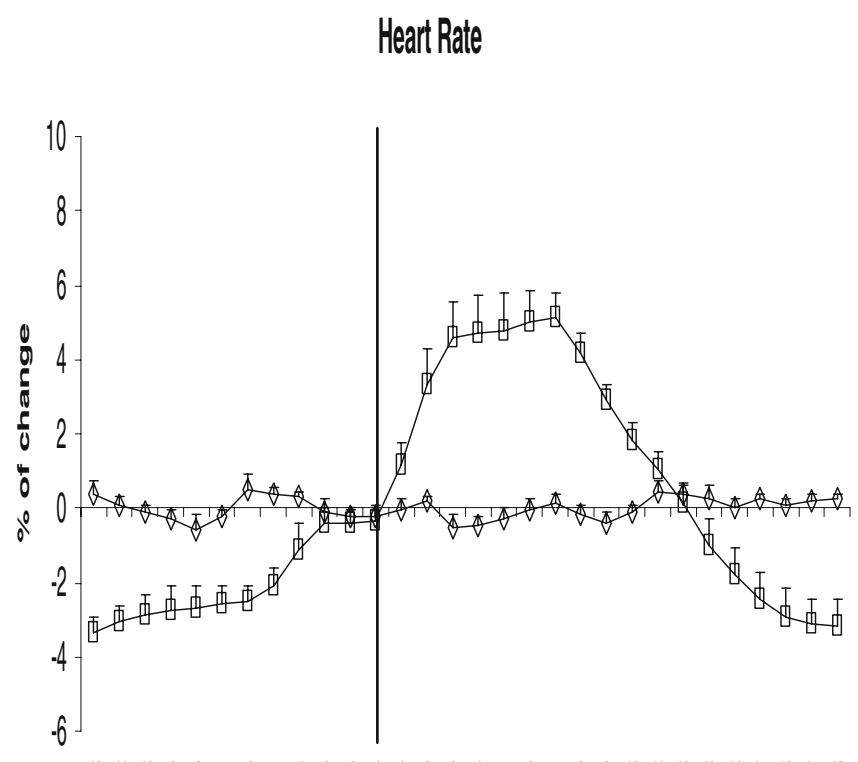

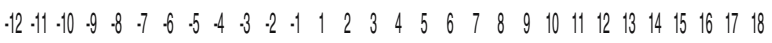

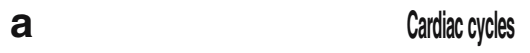

Pulse Wave Amplitude

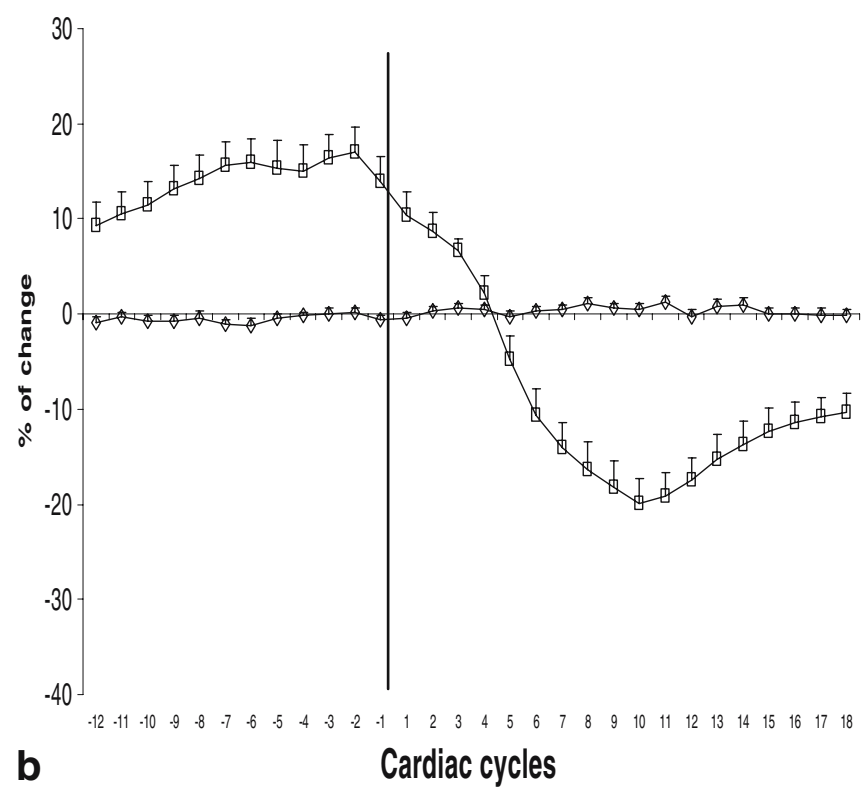

$\diamond$ Non-events $\square$ All events

Fig. 2 a, b Heart rate and pulse wave amplitude responses during stage 2 NREM sleep following "non-events" and obstructive sleep respiratory events (apneas, hypopneas and upper airway resistance episodes). All values are means \pm SEM calculated from all respiratory events within the 12 subjects. All data are expressed as a percentage of the average of the 12 cardiac cycles prior to the end of the event (time zero, vertical line) and the 18 following its end 
peated measure design. The model included a "type of event" effect, a "period" effect (12 measures before vs 18 after the event), a "period $\times$ type of event" interaction term and a repeated "time of measure" effect. This technique allows the simultaneous assessment of several categorical variables while taking into account the fact that measures are not independent and are clustered within each subject. Null hypotheses were rejected when $p<0.05$. All data were reported as means \pm SEM. Analyses were performed with the Stata 8.1, statistical package (Stata Corporation, College Station, Texas 77845, USA).

\section{Results}

Table 1 and Fig. 1 show clinical anthropometric and polysomnographic data and examples of recordings. Patients, aged $45.8 \pm 2.8$ years with a mean BMI of $30.8 \pm 1.3 \mathrm{~kg} / \mathrm{m}^{2}$, had severe SDB with a mean respiratory disturbance index (RDI) of $49.7 \pm 5.2$ respiratory events per hour of sleep.

We analyzed a total of 343 "non-events" and 1,431 respiratory events in stage 2 NREM sleep: $280 \mathrm{OA}, 800 \mathrm{OH}$ and 351 UARE.

Overall, obstructive respiratory events provoked a relative bradycardia followed by a rapid increase in HR, which reached a maximum around seven beats after the end of the event. The mean HR rise after the end of the respiratory event was $6 \pm 0.6 \%$ and the $\Delta$ HR was $9.5 \pm 1 \%$ (Fig. $2 a$ ).

The PWA showed a relative increase during the respiratory event, followed by an intense vasoconstriction. The relative lowest value was reached at about ten cardiac cycles after the end of the event. The mean PWA fall was $-21.4 \pm 2.1 \%$ and the mean $\Delta$ PWA was $-39.8 \pm 4.4 \%$ (Fig. $2 b$ ).
Cardiovascular changes in response to different types of respiratory events

To compare cardiovascular changes following different types of respiratory events, we subdivided the patients into two groups. The first group consisted of six patients presenting essentially $\mathrm{OA}$ and $\mathrm{OH}$, and the second group consisted of those presenting essentially $\mathrm{OH}$ and UARE. The two groups were not significantly different in age (49.6 \pm 4.5 vs $42 \pm 4.4$ years $)$, BMI $(30.5 \pm 0.7$ vs $31.03 \pm 3.1 \mathrm{~kg} /$ $\left.\mathrm{m}^{2}\right)$, Epworth Sleepiness Scale score $(7.3 \pm 1$ vs $9.5 \pm 1.7)$ or RDI (57.7 \pm 8.9 vs $41.7 \pm 7.4 / \mathrm{h}$ of sleep).

Following $\mathrm{OA}$ and $\mathrm{OH}$, and $\mathrm{OH}$ and UARE, there were significant changes over time in HR and PWA. In the first group of patients, the response magnitude of HR and PWA did not vary significantly with the type of respiratory event (time $\times$ type of event interaction, $p>0.2$ ). In the second group, there was no significant difference in changes over time between $\mathrm{OH}$ and UARE (timextype of event interaction, $p>0.3$ : Table 2, Figs. 3, 4).

Cardiovascular changes related to different levels of arousal

The percentage of respiratory events accompanied by a grade 0 arousal was $35.7 \%, 42.3 \%$ by a grade 1 arousal and $21.9 \%$ by a grade 2 arousal. The mean $\mathrm{SaO}_{2}$ fall provoked by respiratory events was similar in the three arousal groups.

Following respiratory events, there were significant changes over time in HR and PWA (time effect, both $p<0.0001$; Fig. 5a) even when these events provoked minor or no-EEG changes (i.e., grade 0 arousal). Overall, the response magnitude of the cardiovascular markers varied

Table 2 Number, respiratory events characteristics and related cardiovascular changes during stage 2 NREM sleep

\begin{tabular}{|c|c|c|c|c|c|c|c|c|c|}
\hline & Number & $\begin{array}{l}\text { Mean per } \\
\text { patient }\end{array}$ & Range & $\begin{array}{l}\text { Duration of } \\
\text { the respiratory } \\
\text { event (s) }\end{array}$ & $\begin{array}{l}\mathrm{SaO}_{2} \mathrm{O} \text { fall } \\
(\%)\end{array}$ & $\begin{array}{l}\text { PWA fall } \\
(\%)\end{array}$ & $\begin{array}{l}\text { HR rise } \\
(\%)\end{array}$ & $\begin{array}{l}\Delta \mathrm{PWA} \\
(\%)\end{array}$ & $\begin{array}{l}\Delta \mathrm{HR} \\
(\%)\end{array}$ \\
\hline OA first group & 279 & $39.8 \pm 11.8$ & $18-82$ & $17.5 \pm 1.6$ & $-9.1 \pm 1.9 £ \dagger$ & $-28.1 \pm 4.9^{\mathrm{a}}$ & $10.3 \pm 2.6^{\mathrm{a}}$ & $-54.8 \pm 10^{\mathrm{b}}$ & $16.7 \pm 4.2^{\mathrm{b}}$ \\
\hline $\mathrm{OH}$ first group & 471 & $78.5 \pm 27$ & $25-162$ & $18.5 \pm 1.6$ & $-5.9 \pm 0.43 * \dagger$ & $-19.8 \pm 9.2^{\mathrm{a}}$ & $6 \pm 1.3^{\mathrm{a}}$ & $-37.3 \pm 8.3^{\mathrm{b}}$ & $9.7 \pm 2.1^{\mathrm{b}}$ \\
\hline $\mathrm{OH}$ second group & 329 & $54.8 \pm 15$ & $22-93$ & $19.5 \pm 2.1$ & $-5.4 \pm 0.4 * \dagger$ & $-28.9 \pm 5.2^{\mathrm{a}}$ & $6.3 \pm 1.1^{\mathrm{a}}$ & $-53.2 \pm 9.5^{\mathrm{b}}$ & $10.3 \pm 1.8^{\mathrm{b}}$ \\
\hline UARE second group & 191 & $27.6 \pm 5.2$ & $12-39$ & $19.5 \pm 1$ & $-1 \pm 0.2 * £$ & $-19.2 \pm 3.5^{\mathrm{a}}$ & $3.7 \pm 1^{\mathrm{a}}$ & $-36.2 \pm 6.7^{b}$ & $6.2 \pm 1.3^{\mathrm{b}}$ \\
\hline Grade 0 arousal & 529 & $48.9 \pm 8.5$ & $26-105$ & $18.5 \pm 1.1$ & $-4.3 \pm 0.6$ & $-13.4 \pm 2.1 \neg t^{\mathrm{a}}$ & $4.2 \pm 0.7^{\mathrm{a}}$ & $-26 \pm 4.4 \neg t^{\mathrm{b}}$ & $6.5 \pm 1^{b}$ \\
\hline Grade 1 arousal & 603 & $54 \pm 8.6$ & $31-112$ & $19 \pm 0.9$ & $-4.4 \pm 0.75$ & $-23.4 \pm 2 \S \neg \dagger^{\mathrm{a}}$ & $6.6 \pm 1^{\mathrm{a}}$ & $-42.4 \pm 4.3 \S \neg t^{\mathrm{b}}$ & $10.1 \pm 1.5^{\mathrm{b}}$ \\
\hline Grade 2 arousal & 299 & $28 \pm 4.7$ & $9-48$ & $21.4 \pm 1.2$ & $-4.6 \pm 0.88$ & $-34 \pm 2.3 \S^{\mathrm{a}}$ & $7.5 \pm 0.8^{\mathrm{a}}$ & $-62.9 \pm 5 \S^{\mathrm{b}}$ & $13.3 \pm 1.4^{\mathrm{b}}$ \\
\hline
\end{tabular}

Symbols indicate a significant difference compared to OA $\left(^{*}\right), \mathrm{OH}(£)$, UARE $(\dagger)$, grade 0 arousal $(\S)$, grade 1 arousal $(\neg)$ and grade 2 arousal $(\$)$

$O A$ Obstructive apnea, $O H$ obstructive hypopnea, $U A R E$ upper airway resistance episode, first group patients presenting $\mathrm{OA}$ and $\mathrm{OH}(n=6)$, second group patients presenting OH and UARE $(n=6)$, Grade 0 arousal minor EEG changes $(<3$ s), Grade 1 arousal shift in EEG

frequency lasting from 3-10 s, Grade 2 arousal shift in EEG frequency lasting $>10 \mathrm{~s}$

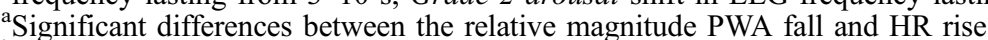

${ }^{\mathrm{b}}$ Differences between the relative magnitude $\triangle \mathrm{PWA}$ and $\Delta \mathrm{HR}$ 
Heart Rate

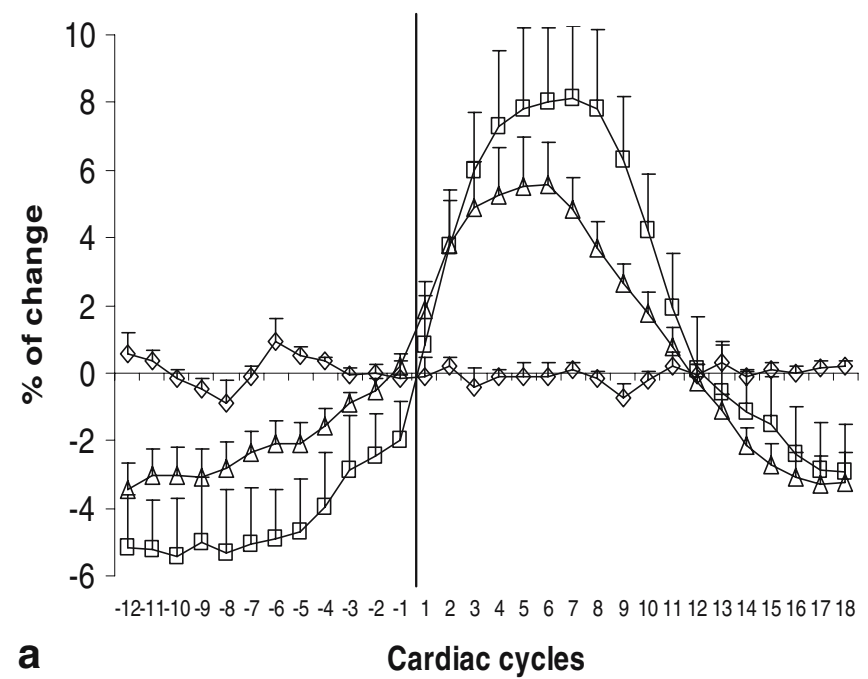

\section{Pulse Wave Amplitude}

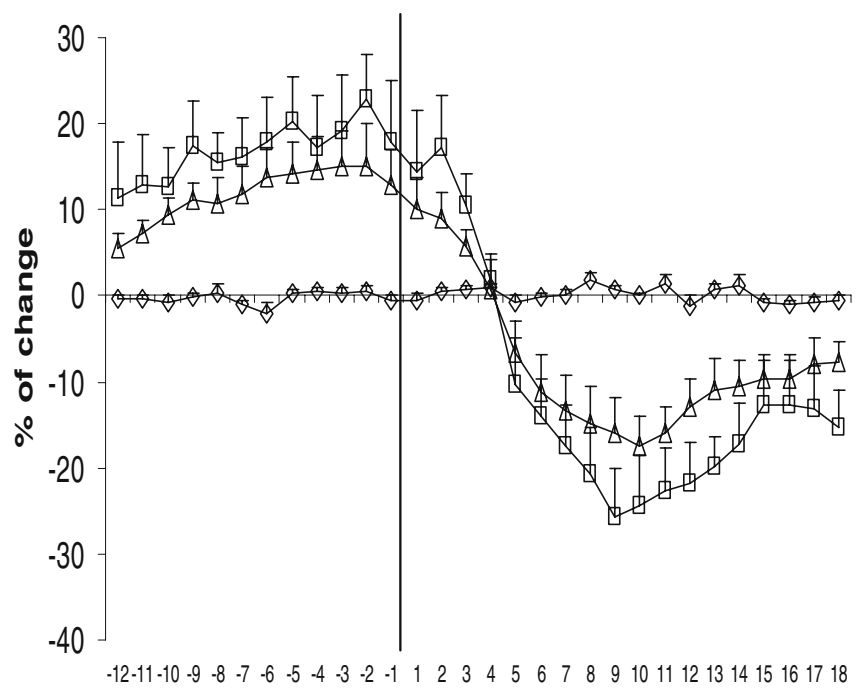

b

Cardiac cycles

\section{$\diamond$ Non-events $\square$ Apnea $\Delta$ Hypopnea}

Fig. 3 a, b Heart rate and pulse wave amplitude responses to obstructive apneas $(\mathrm{OA})$ and obstructive hypopneas $(\mathrm{OH})$. All values are means \pm SEM calculated from $\mathrm{OA}$ and $\mathrm{OH}$ within subjects presenting essentially these two types of respiratory events during sleep (group 1). All data are expressed as a percentage of the average of the 12 cardiac cycles prior to the end of the event (time zero, vertical line) and the 18 following its end

with the category of arousal (time $\times$ category interaction, both $p<0.0001$; Fig. 5).

PWA fall and $\triangle$ PWA were significantly greater with longer arousals (grade 0 vs grade $1, p<0.05$; grade 0 vs

\section{Heart Rate}

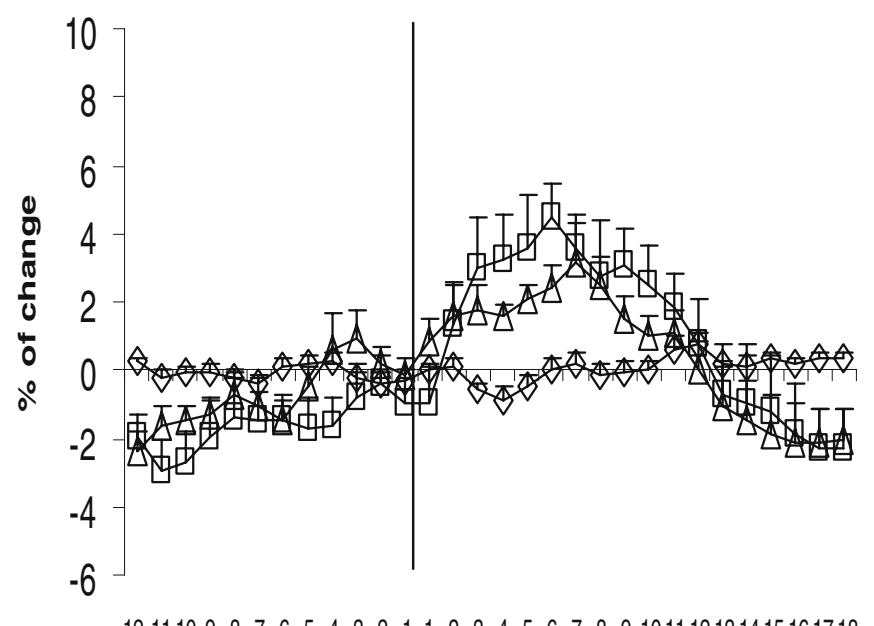

Cardiac cycles

\section{Pulse Wave Amplitude}

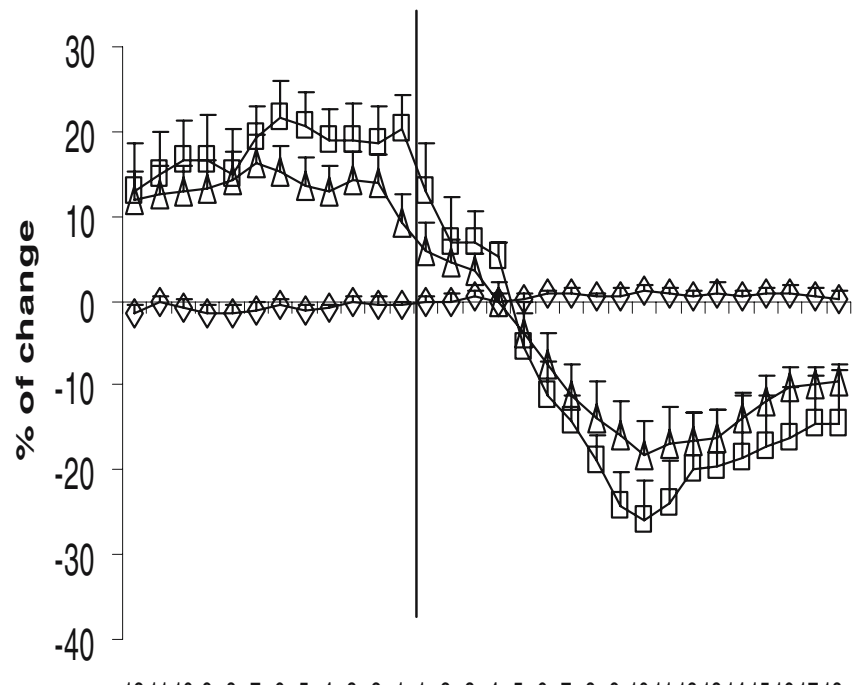

b

Cardiac cycles

\section{$\diamond$ Non-events $\square$ Hypopnea $\triangle$ UARE}

Fig. 4 a, b Heart rate and pulse wave amplitude responses to obstructive hypopneas $(\mathrm{OH})$ and upper airway resistance episodes $(U A R E)$. All values are means \pm SEM calculated from $\mathrm{OH}$ and UARE within subjects presenting essentially these two types of respiratory events during sleep (group 2). All data are expressed as a percentage of the average of the 12 cardiac cycles prior to the end of the event (time zero, vertical line) and the 18 following its end

grade $2, p<0.001$; grade 1 vs grade $2, p<0.05$ ). However, maximal HR rise and $\Delta \mathrm{HR}$ were not significantly different between different levels of arousal (Table 2). 


\section{Heart Rate}

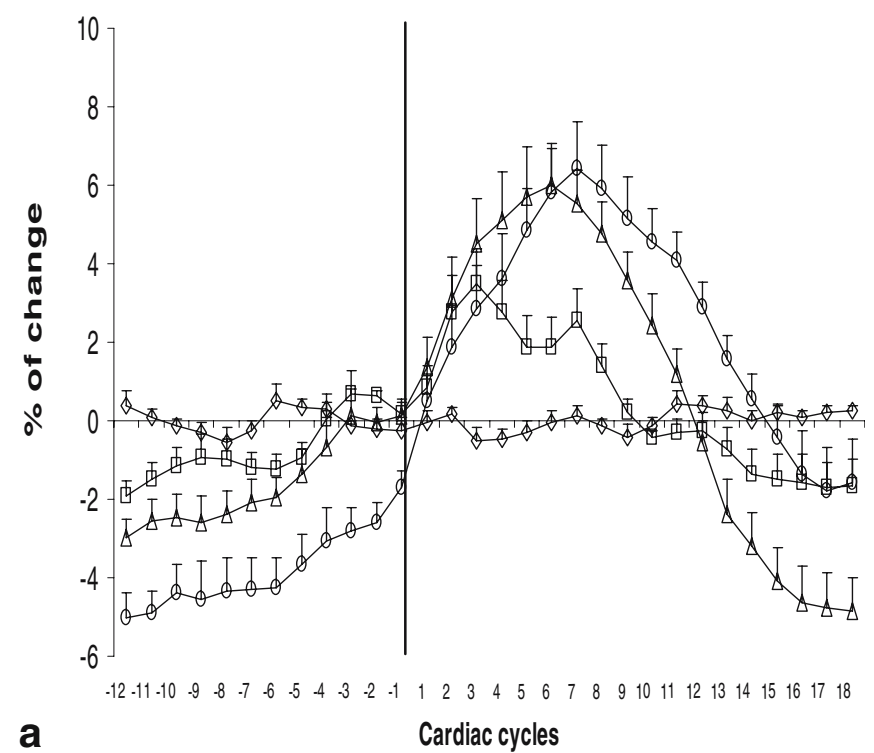

Pulse Wave Amplitude

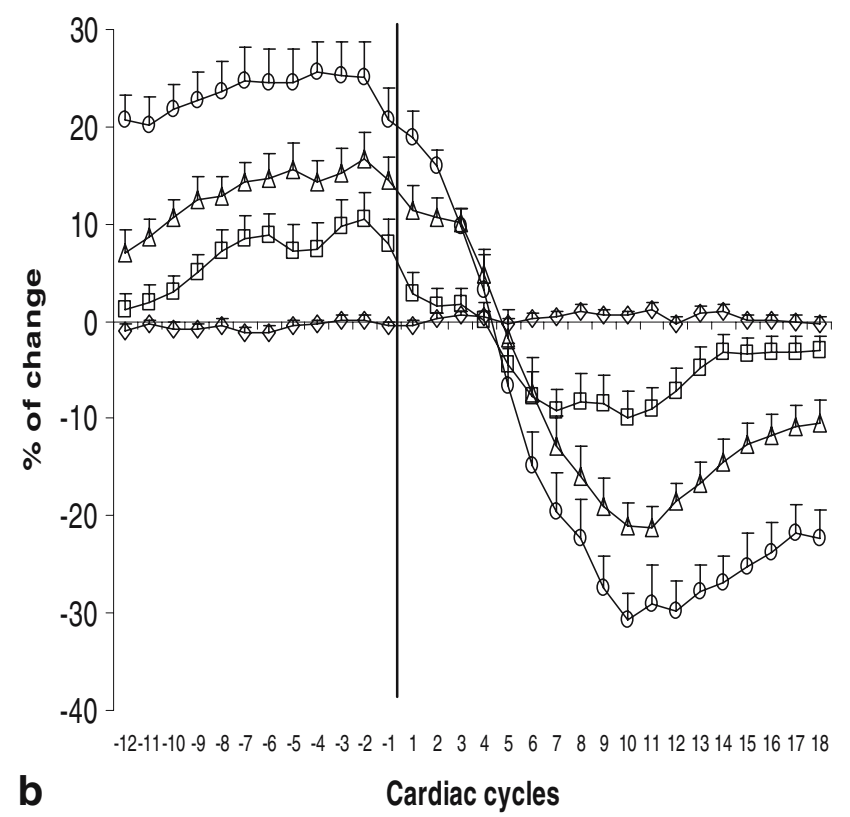

$\begin{array}{|ll|}\diamond \text { Non-events } & \square \text { Grade } 0 \text { arousal } \\ \Delta \text { Grade } 1 \text { arousal } & \text { O Grade } 2 \text { arousal }\end{array}$

Fig. 5 a, b Heart rate and pulse wave amplitude responses to obstructive respiratory events according to grade of associated arousal. All values are means \pm SEM calculated within each subject $(n=12$ subjects). All data are expressed as a percentage of the average of the 12 cardiac cycles prior to the end of the event (time zero, vertical line) and the 18 following its end
With each grade of arousal, variations in PWA parameters were always significantly greater than variations in HR parameters (Table 2): following grade 0 arousal, PWA fall was $-13.4 \pm 2.1 \%$ and HR rise $4.2 \pm 0.7 \%(p<0.0001)$, $\triangle \mathrm{PWA}-26 \pm 4.4 \%$ and $\triangle \mathrm{HR} 6.5 \pm 1 \%(p<0.0001)$; following grade 1 arousal, PWA fall was $-23.4 \pm 2 \%$ and HR rise $6.6 \pm 1 \%(p<0.0001), \Delta \mathrm{PWA}-42.4 \pm 10.1 \%$ and $\Delta \mathrm{HR}$ $10.1 \pm 1.5 \%(p<0.0001)$; following grade 2 arousal, PWA fall was $-34 \pm 2.3 \%$ and HR rise $7.5 \pm 0.8 \%(p<0.0001)$, $\triangle$ PWA $-62.9 \pm 5 \%$ and $\Delta$ HR $13.3 \pm 1.4 \%(p<0.0001)$.

\section{Discussion}

The principal findings of our study are, first, that measuring finger PWA by photoplethysmography shows particularly marked changes related to obstructive sleep respiratory events in NREM sleep. HR also shows clear changes, but of smaller magnitude. These changes occur even when there are no discernible cortical arousals according to the ASDA definition, although these events may be functionally important [14]. Second, the magnitude of these changes seems to be related to the intensity of central nervous activation and not to the type of respiratory event.

Techniques currently employed for investigating patients with suspected SDB are frequently expensive, labor intensive and may not accurately detect sleep fragmentation associated with respiratory events [13]. The arousal process that occurs in response to sleep respiratory events begins at the brain stem level with a reflex increase in sympathetic activity, causing changes in a number of measurable variables (BP, HR, skin vasoconstriction) [24]. This may be the only level of response, although, for other respiratory events, the arousal stimulus may radiate upwards to involve the cortex, causing changes in EEG. Previous works have suggested that there could be other markers of arousal which are much easier to measure than EEG and which could assess the true extent of sleep fragmentation. This is the case for the pulse transit time, a non-invasive measure of blood pressure, a semiquantitative measure of respiratory effort [25-27] and a sensitive marker of autonomic arousals [20]. The recently developed peripheral arterial tonometry, based on detection of peripheral vasoconstriction, has been shown to be a sensitive marker of sympathetic arousal [28] and apneas $[9,29]$. In our study, we evaluated changes in peripheral arterial volume by photoplethysmography using a standard oxymeter. It measures the relative absorption of red light and infrared light by hemoglobin $(\mathrm{Hb})$ and $\mathrm{HbO}_{2}$. The system utilizes the fact that arterial blood flow pulsates and other fluids and tissues do not. The pulsation of the arterial blood flow modulates light passing through it. The attenuation of light energy due to arterial blood flow can be detected and isolated, can be converted to an electronic signal for calculation of $\mathrm{SaO}_{2}$ and provides a semiquantitative measure of pulse wave amplitude [30]. Without pur- 
chasing additional equipment, the pulse wave amplitude can easily be recorded using most conventional pulse oxymeters already in sleep-laboratory use, and there is no need for high sampling rates or complex algorithms.

In our study, the overall magnitude and pattern of HR and PWA responses were not significantly different between $\mathrm{OA}$ and $\mathrm{OH}$, or $\mathrm{OH}$ and UARE, although OA provoked a more important oxygen desaturation. Previously, other studies have shown that mild hypoxia did not alter the magnitude or time course of acute changes in cardiovascular parameters following acoustically induced arousal [23]. However, the pattern of cardiovascular response was different depending on the level of arousal associated with the respiratory event, with longer arousals provoking higher PWA and HR changes. These findings are in accordance with others reports regarding the magnitude of the cardiovascular response related to changes in EEG $[6,10,13,14$, 19, 20].

PWA increased during obstructive breathing events, suggesting vasodilation, followed by an intense vasoconstriction, slightly delayed with respect to HR. This pattern has also been already described [31], although another study did not report the apparent dilatory response during the respiratory event [29]. One possible explanation of this vasodilation is the result of a return to baseline values after the sharp decline caused by the preceding arousal. In our study, it must be kept in mind that each value is normalized with respect to the average over 30 cardiac cycles. This apparent vasodilation could result from such an averaging process. This may also account for the finding that the cardiovascular changes during the respiratory event differ with the level of arousal: higher cardiovascular changes concomitant with longer arousals lead to higher average values. As each value is expressed as a percentage of this average, in longer arousals, the values preceding the end of the event are influenced by the higher averaged value. Another possible explanation could be that we observed that the mean duration of the respiratory events preceding longer arousals showed a trend to be higher than the duration of events preceding shorter arousals. Davies et al. [7] showed that apnea length was an independent predictor of blood pressure rise. They suggested that because the stimulus required for causing arousal increases with the depth of NREM sleep, longer apneas (during which sleep has had longer to become established) may require a more intense arousal response for their termination and, thus, lead to larger peripheral autonomic effects. Thus, longer respiratory events may provoke higher respiratory effort, and then become more important arousal stimuli, but also provoke greater cardiovascular variations during the respiratory event.

Several limitations need to be acknowledged with respect to the present study. First, the classification of EEG arousals remains quite arbitrary and inevitably subjective. Quantitative EEG techniques might provide a more sensitive approach to detect EEG changes that are not visually discernible or not conventionally considered as arousal. Another limitation is derived by the difficulties imposed by the lack of a stable baseline from which to compare the different responses in terms of relative response magnitudes. We tested previously in a subsample of events other average approaches to calculate a baseline (as a "nonevent" baseline, the average of the ten cardiac cycles at the beginning of the event and the ten at the end), obtaining similar results. The fact remains that this somewhat arbitrary baseline allows the detection of cardiovascular changes related to respiratory events. Third, this study was restricted to the analysis of the cardiovascular response around the end of previously detected sleep respiratory events in a small population. Several factors, such as age, neurological diseases disturbing the autonomic nervous system or ingestion of cardiovascular drugs, may limit the use of the PWA as a marker. Finally, we did not analyze events in REM sleep, where cardiovascular responses show substantial differences [6]. Although our results suggest that PWA changes measured by photoplethysmography would be a practical method of evaluating sleep fragmentation related to obstructive respiratory events, it has to be confirmed in larger clinical populations.

In summary, this study shows that, in NREM sleep, obstructive respiratory events provoke substantial changes in finger pulse waveform easily measured by photoplethysmography. The relative magnitude of these changes varied with the grade of induced arousal. PWA changes were also seen in the absence of conventionally scored EEG arousals. The amplitude of the photoplethysmogram pulse waveform may be a simple and sensitive marker of sleep fragmentation due to obstructive respiratory events.

Acknowledgements We thank the Délégation Valaisanne de la Loterie Romande for financial support and John Brunton for his help in manuscript preparation. José Haba-Rubio received for this work the Weinmann award of the French Sleep Research Society at their XVIII meeting. The authors declare that they have no conflicts of interest. 


\section{References}

1. ASDA (1999) Sleep-related breathing disorders in adults: recommendations for syndrome definition and measurement techniques in clinical research. Sleep 22:667-689

2. Guilleminault C, Stoohs R, Clerk A, Cetel M, Maistros P (1993) A cause of excessive daytime sleepiness. The upper airway resistance syndrome. Chest 104:781-787

3. Phillipson EA, Sullivan CE (1978) Arousal: the forgotten response to respiratory stimuli. Am Rev Respir Dis 118:807-809

4. Remmers JE, deGroot WJ, Sauerland EK, Anch AM (1978) Pathogenesis of upper airway occlusion during sleep. J Appl Physiol 44:931-938

5. Guilleminault C, Rosekind M (1981) The arousal threshold: sleep deprivation, sleep fragmentation, and obstructive sleep apnea syndrome. Bull Eur Physiopathol Respir 17:341-349

6. Johnson LC, Lubin A (1967) The orienting reflex during waking and sleeping. Electroencephalogr Clin Neurophysiol 22:11-21

7. Davies RJ, Belt PJ, Roberts SJ, Ali NJ, Stradling JR (1993) Arterial blood pressure responses to graded transient arousal from sleep in normal humans. J Appl Physiol 74:1123-1130

8. Badr MS, Morgan BJ, Finn L, Toiber FS, Crabtree DC, Puleo DS, Skatrud JB (1997) Ventilatory response to induced auditory arousals during NREM sleep. Sleep 20:707-714

9. Schnall RP, Shlitner A, Sheffy J, Kedar R, Lavie P (1999) Periodic, profound peripheral vasoconstriction - a new marker of obstructive sleep apnea. Sleep 22:939-946

10. Catcheside PG, Chiong SC, Mercer J, Saunders NA, McEvoy RD (2002) Noninvasive cardiovascular markers of acoustically induced arousal from nonrapid-eye-movement sleep. Sleep 25:797-804

11. Loredo JS, Clausen JL, Ancoli-Israel S, Dimsdale JE (1999) Night-to-night arousal variability and interscorer reliability of arousal measurements. Sleep 22:916-920
12. Bonnet $\mathrm{M}$ et al (1992) EEG arousals: scoring rules and examples: a preliminary report from the Sleep Disorders Atlas Task Force of the American Sleep Disorders Association. Sleep 15:173-184

13. Douglas NJ, Martin SE (1996) Arousals and the sleep apnea/hypopnea syndrome. Sleep 19(Suppl 10):S196S197

14. Martin SE, Wraith PK, Deary IJ, Douglas NJ (1997) The effect of nonvisible sleep fragmentation on daytime function. Am J Respir Crit Care Med 155:1596-1601

15. Levy P, Pepin JL (2003) Sleep fragmentation: clinical usefulness of autonomic markers. Sleep Med 4:489 491

16. Somers VK, Mark AL, Zavala DC, Abboud FM (1989) Influence of ventilation and hypocapnia on sympathetic nerve responses to hypoxia in normal humans. J Appl Physiol 67:2095-2100

17. Somers VK, Mark AL, Zavala DC, Abboud FM (1989) Contrasting effects of hypoxia and hypercapnia on ventilation and sympathetic activity in humans. J Appl Physiol 67:2101-2106

18. Rechtschaffen A, Kales A (1968) A manual of standardized terminology, technique and scoring system for sleep stages of human sleep. Brain Information Service, Brain Research Institute, Los Angeles

19. Lofaso F, Goldenberg F, d'Ortho MP, Coste A, Harf A (1998) Arterial blood pressure response to transient arousals from NREM sleep in nonapneic snorers with sleep fragmentation. Chest 113:985-991

20. Pitson D, Chhina N, Knijn S, van Herwaaden M, Stradling J (1994) Changes in pulse transit time and pulse rate as markers of arousal from sleep in normal subjects. Clin Sci 87:269-273

21. Pitson DJ, Stradling JR (1998) Autonomic markers of arousal during sleep in patients undergoing investigation for obstructive sleep apnoea, their relationship to EEG arousals, respiratory events and subjective sleepiness. J Sleep Res 7:5359
22. Jelic S, Bartels MN, Mateika JH, Ngai P, DeMeersman RE, Basner RC (2002) Arterial stiffness increases during obstructive sleep apneas. Sleep 25:850 855

23. Catcheside PG, Chiong SC, Orr RS, Mercer J, Saunders NA, McEvoy RD (2001) Acute cardiovascular responses to arousal from non-REM sleep during normoxia and hypoxia. Sleep 24:895902

24. Hilton SM (1982) The defence-arousal system and its relevance for circulatory and respiratory control. J Exp Biol 100:159-174

25. Pitson DJ, Sandell A, van den Hout R, Stradling JR (1995) Use of pulse transit time as a measure of inspiratory effort in patients with obstructive sleep apnoea. Eur Respir J 8:1669-1674

26. Argod J, Pepin JL, Levy P (1998) Differentiating obstructive and central sleep respiratory events through pulse transit time. Am J Respir Crit Care Med 158:1778-1783

27. Argod J, Pepin JL, Smith RP, Levy P (2000) Comparison of esophageal pressure with pulse transit time as a measure of respiratory effort for scoring obstructive nonapneic respiratory events. Am J Respir Crit Care Med 162:87-93

28. Lavie P, Schnall RP, Sheffy J, Shlitner A (2000) Peripheral vasoconstriction during REM sleep detected by a new plethysmographic method. Nat Med 6:606

29. Bar A, Pillar G, Dvir I, Sheffy J, Schnall RP, Lavie P (2003) Evaluation of a portable device based on peripheral arterial tone for unattended home sleep studies. Chest 123:695-703

30. Middleton PM, Henry JA (2000) Pulse oximetry: evolution and directions. Int J Clin Pract 54:438-444

31. Grote L, Zou D, Kraiczi H, Hedner J (2003) Finger plethysmography - a method for monitoring finger blood flow during sleep disordered breathing. Respir Physiol Neurobiol 136:141-152 